\title{
QUANTITATIVE ASSESSMENT OF THE CONCENTRATED EMPLOYMENT PROGRAM*
}

Lawrence H. Revzan**

Operations Research, Incorporated

\section{Introduction}

The purpose of this study was to perform a quantitative evaluation of the first year Concentrated Employment Program (CEPI). ${ }^{1}$ The CEP represents an attempt by the Department of Labor (DOL) to coordinate several manpower development and training services into an integrated delivery system as opposed to the traditional "single service" approach of previous (and some subsequent) training programs. Therefore, a complete evaluation of CEP must not only weigh alternatives to utilizing resources within the program; it must also address directly the advantages and disadvantages of the integrated approach as a basis for comparing CEP to programs that employ the "traditional" approach to manpower training.

The assessment presented in this paper is designed to satisfy the first evaluation objective by relating the program benefits received by individuals according to their personal characteristics, the different types of services provided, and geographic location of training with the costs associated with each of these dimensions. Hence, whereas most studies of manpower training have focused solely on impact, i. e., benefits versus $\cos t, 2$ this study deals with both impact and the underlying social production process (or production function $)^{3}$ in an attempt to explain the reasons for the wide range of observed results.

Before developing the basic evaluation model, some further background pertaining to CEP operating objectives is warranted. As stated by the Department of Labor:

The prime end objective of the Concentrated Employment effort (Program) is jobs, permanent, unsubsidized jobs at decent wage rates with opportunity for upward movement... in the public or private sector, preferably the latter. 4

This objective has a number of dimensions that must be fully developed.

a. The first dimension of the objectives establishes a target group and a target a rea. Part of the performance measurement of CEP depends on its success in concentrating the delivery of manpower and supportive services to these limited areas and groups.

b. Since the education, skill and experience of the target populations do not match well with the requirements of most jobs, the second dimension of the objective is a comprehensive and sequential program of en rollee services. Because CEP emphasizes the individual approach, it is imperative that each enrollee receive the particular mix of services he is judged to require.

c. The third dimension of the objective is the nature of the jobs into which enrollees are placed. For CEP simple job placement is insufficient. The job must provide the en rollee with sufficient income (or near-term income growth) for him to be self-supporting. It must also provide sufficient growth prospects and/or stability to produce significant long-term periods of employment. 


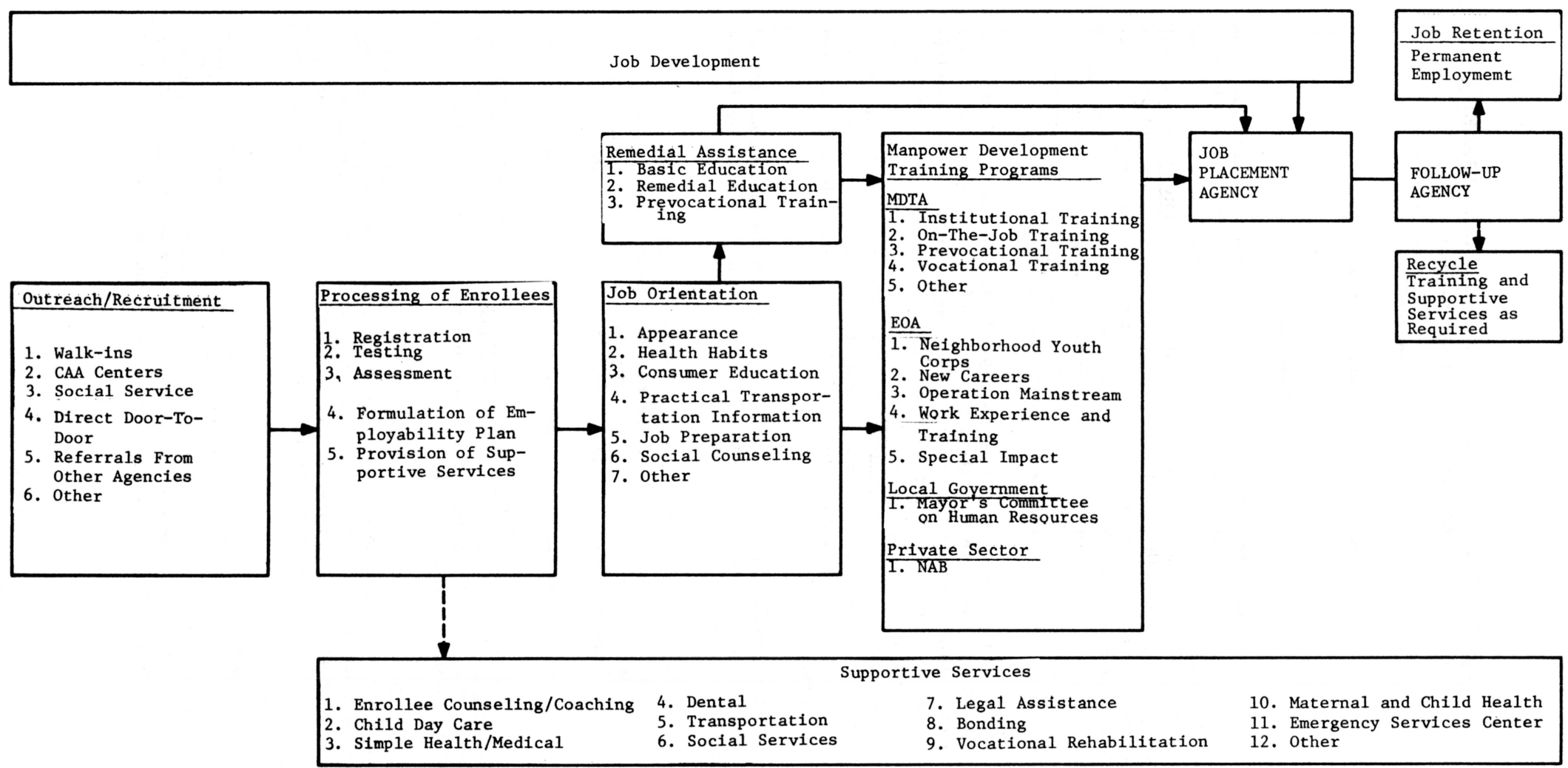


Figure I provides a visual description of an idealized CEP process, depicting the service components available to an enrollee and the path through which the enrollee passes in receiving these services. An enrollee, however, may bypass some areas, recycle through some components, and/or be held in some areas for lengthy periods as a result of "bottlenecks" in the physical production process. It is through the operation of this complex set of services that resources are utilized (costs incurred) and the human capital of the enrollees augmented (leading to future benefits). Thus, the process must be fully developed and understood to answer the why question pertaining to training in addition to the questions of general resource allocation (benefits versus costs) and income distribution (benefits received and costs incurred by whom).

The paper is divided into three sections: Section II discusses the physical CEP production process in more detail in terms of the observed flow of enrollees processed by the sample projects observed, the benefits and costs associated with the process, and the data problems pertaining to their estimation; Section III presents some hypotheses pertaining both to individual and project performance utilizing sample data; and Section IV presents the planning implications of the study findings and some of the recommendations made to the Department of Labor pertaining to program operations, administration, and information flow.

\section{CEP Process Model, Benefits, and Costs}

The quantity of information necessary to observe whether a project is in fact meeting the above stated objectives is extensive, requiring both intensive work utilizing cross-section data and follow-up research over time. The required knowledge and quantitifaction of such diverse factors as labor market conditions, institutional barriers to advancement, changing technology, and overall economic performance make concentration on development of the process model more significant, since questions pertaining to "long term benefits attributable to the program" offer particularly difficult problems in research design no matter how long experimental and control groups may be followed and in how many different situations behavior is observed. While attempting to examine all of the above factors in depth, the research effortwas limited primarily to the CEP production process as it was designed and to its operation through the sampling of enrollee movement from CEP records at the project site.

\section{A. The Process Model}

The CEP Process model deals with four elements of training:

a. the CEP delivery system developed in terms of its component parts;

b. the characteristics of enrollees on program entry;

c. the paths enrollees follow through the CEP process in progressing to successful or unsuccessful program completion;

d. the end products of CEP processing, i. e., whether an individual is successfully placed, drops out, or is recorded as holding (still enrolled) in some component, and the relation of these "end-state" results to the paths followed by the enrollees.

Figure II presents a simplified logic flow of a portion of an enrollee's movement through the complex process, where specific programs refer to the components highlighted in Figure I. 5 


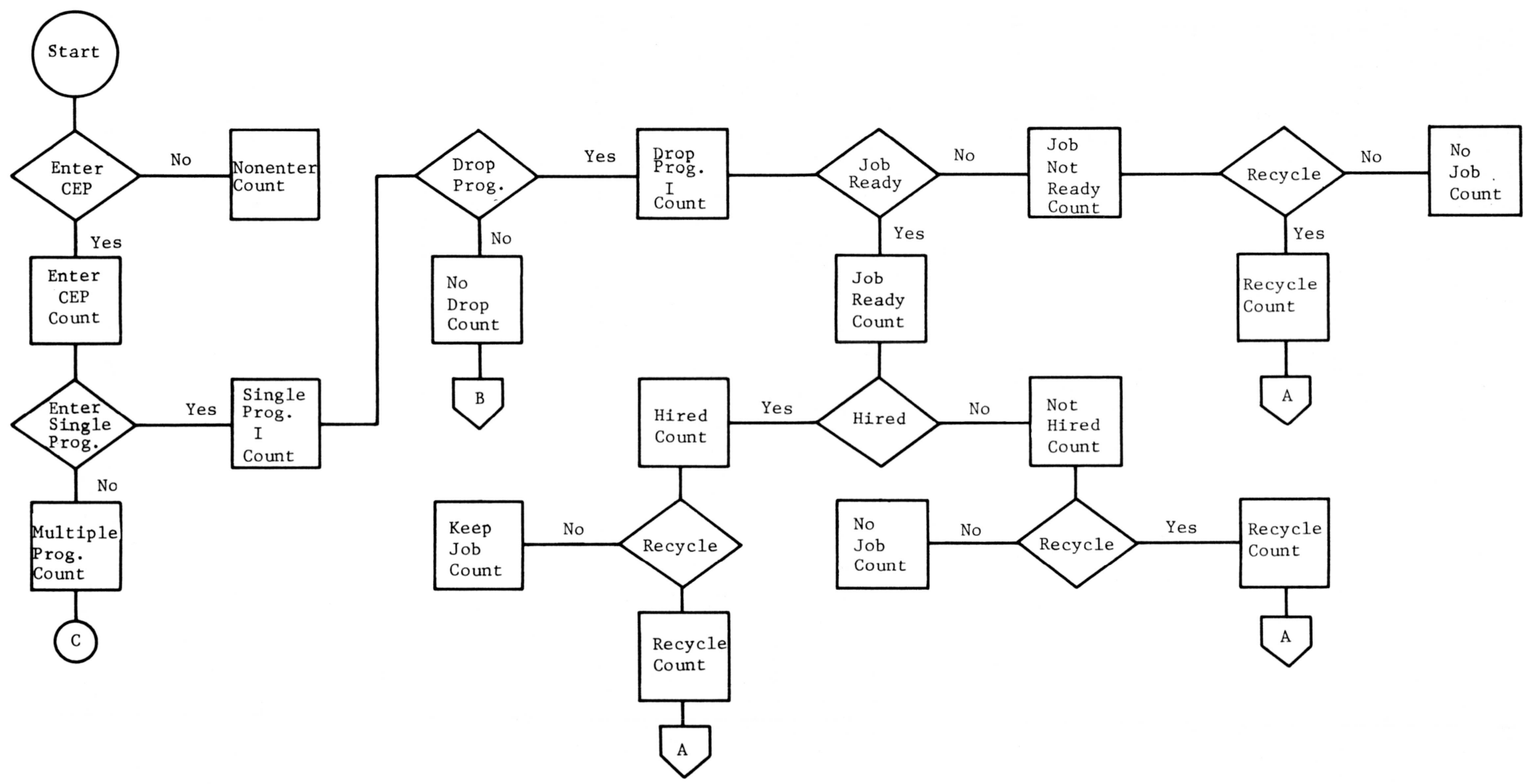

* "Prog." abbreviation for "Programs"

** "Programs" in the diamond-shaped boxes refer to CEP training components, e.g., Orientation, OJT. 
The CEP operating model presents a detailed logic flow of the possible paths that can be followed by a representative enrollee through the program process. The diagram consists of a series of decision points (the diamondshaped entries in the figure), the outcomes of which are movements to either intermediate points within the CEP or program termination (end states). For example, whethe $r$ a program participant completes Orientation or drops out would constitute a decision point. The individual enrollee outcomes can be summarized at each decision point based on field observations of enrollee progress. For example, if 50 enrollees enter Orientation, of whom 30 complete and 20 drop out, the conditional probability of completion (given entry into the component) is $0.6(30 / 50)$ and the probability of drop-out is $0.4(20 / 50)$. These transition probabilities were computed at each decision point based on the enrollee sample.

Similarly, the time spent by the enrollee in the CEP system can be computed and divided into the following two general components?

a. time spent within a training class, i.e., the usual duration of Orientation is two weeks; this element would be recorded at the relevant decision point, e.g., at Orientation;

b. time spent waiting (or "holding") for an available slot in a training component and possibly recycling through a component while waiting; this element would be recorded on the connection between the decision points.

These particular data were not available in sufficient detail from center records to enable these calculations to be made with accuracy. However, using the above model, both service (generally construed) and waiting times could be computed for each program participant at and between decision points, the results summed for all enrolless, and the probability distribution (and parameters) of these times determined.

It can readily be seen that the treatment of a complex training program in the above manner will lead to a detailed set of observations pertaining to the actual operation of the system itself. Hence, the computation of costs associated with each service and their relation to enrollee progress at each point (looking at enrollees with different demographic characteristics and skills) would permit the answering of questions pertaining to internal efficiency as well as the traditional questions pertaining to between program comparisons or program performance against some "absolute" allocative criterion (e.g., do discounted benefits exceed discounted costs for the program as a whole?).

\section{B. Application of Model to Sample Data: Illustrations}

Data pertaining to physical processing of enrollees we re obtained from a sample of approximately 300 enrollees per site from the CEP central records units. 6 Eight socio-economic classes were defined, based on the Manpower Administration's "disadvantaged person" criteria. These are listed in Table I below.

TABLE I - DEFINITION OF CEP ENROLLEE CLASSES

\begin{tabular}{ccccc}
\hline Class & Age & Sex & Ethnic Background & Handicap \\
\hline 1 & Under 22 & Male & Minority & No \\
2 & $22-44$ & Male & Minority & No \\
3 & Over 44 & Male & Minority & No \\
4 & Under 22 & Female & Minority & No \\
5 & $22-44$ & Female & Minority & No \\
6 & Over 44 & Female & Minority & No
\end{tabular}

$7 \quad$ All other disadvantaged enrollees

$8 \quad$ Nondisadvantaged en rollees 
The sampled enrollees were then categorized according to their "class" as they were drawn with no attempt made to select an equal number of enrollees for each class. Hence, the observations for the sample of 300 were assumed to be statistically representative of that particular CEP project's participants during the sample period.

Information regarding the economic characteristics of program participants was collected for each class and city for which the data were available. These characteristics include:
a. age, sex, and education level;
b. distribution of enrollee entering income;
c. weeks unemployed prior to en rollment.

A wide range of values was observed among the projects for each of these variables. For example, the sex distribution ranged from a 70-21 percent male dominance to a 23-77 percent female dominance, with ten cities having male majorities and nine female majorities. In addition, entering income of enrollees varied widely both by city and enrollee characteristics. Thus, it can be seen that the disaggregation of data along these lines might be useful in explaining the observed program outcomes and obtaining a fuller explanation of relative "performance."

Table II illustrates the use of the flow process in recording enrollee physical movement. The columns indicate the three "end-states" of the enrollee--obtained a job; dropped out or was not placed; status not determined from records. The rows indicate the component which the enrollee last utilized. Thus 91 of the 2253 enrollees in the sample ${ }^{7}$ left the program immediately after being processed and were placed; 76 dropped out immediately; and the status of 44 could not be determined from records.

TABLE II - PROBABILITY OF TERMINATION AT PARTICULAR END-STATE ${ }^{\mathrm{a}}$

\begin{tabular}{|c|c|c|c|c|c|c|c|c|}
\hline End State & $\begin{array}{r}\text { Job } \\
\text { Count }\end{array}$ & Pct. & $\begin{array}{r}\text { Dro } \\
\text { Count }\end{array}$ & $\begin{array}{l}\text { op } \\
\text { Pct. }\end{array}$ & $\begin{array}{l}\text { Unkn } \\
\text { Count }\end{array}$ & $\begin{array}{l}\text { own } \\
\text { Pct. }\end{array}$ & $\begin{array}{c}\text { Row } \\
\text { Count }\end{array}$ & $\begin{array}{l}\text { Total } \\
\text { Pct. }\end{array}$ \\
\hline Intake & 91 & 43.1 & 76 & 36.0 & 44 & 20.9 & 211 & 9.4 \\
\hline Orientation & 247 & 46.9 & 184 & 34.9 & 96 & 18.2 & 527 & 23.4 \\
\hline Basic Education & 75 & 24.8 & 186 & 61.4 & 42 & 13.9 & 303 & 13.4 \\
\hline MDTA INST $\mathbf{b}$ & 78 & 37.0 & 48 & 22.7 & 85 & 40.3 & 211 & 9.4 \\
\hline MDTA OJT ${ }^{b}$ & 34 & 56.7 & 16 & 26.7 & 10 & 16.7 & 60 & 2.7 \\
\hline $\mathrm{NYC}^{\mathrm{b}}$ & 122 & 42.7 & 134 & 46.9 & 30 & 10.5 & 286 & 12.7 \\
\hline New Careers & 56 & 52.8 & 38 & 35.8 & 12 & 11.3 & 106 & 4. 7 \\
\hline Special Impact & 58 & 50.4 & 45 & 39.1 & 12 & 10.4 & 115 & 5.1 \\
\hline Other & 135 & 42.6 & 132 & 41.6 & 50 & 15.8 & 317 & 14.1 \\
\hline Test Cities & 110 & 94.0 & 6 & 5.1 & 1 & .9 & 117 & 5.3 \\
\hline Column Totals & 1006 & 44.7 & 865 & 38.4 & 382 & 17.0 & 2253 & 100.0 \\
\hline
\end{tabular}

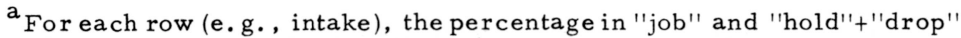
sum to 100 (e.g. , 43.1+20.9+36.0 = 100). The percentage in the final column ("row count") is the percentage of all enrollees who terminated in that end state (e.g., $211 / 2253=9.4$ percent). Data for seven southern and far western cities only.

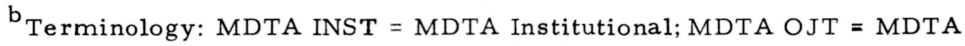
On The Job Training; NYC = Neighborhood Youth Corps. 
Table III provides an alternative way of viewing enrollee movement. In this table, all class 1 participants (young male minority group members) who were placed in Neighborhood Youth Corps (NYC) by CEP are grouped according to the same three "end states" as developed previously and the path they took to reach that position. From the table it can be seen that 82 of the 119 enrollees in this category weresent directly to NYC utilizing none of the CEP supportive services available. This type of finding indicates that in many cases CEP was utilized as a placement service for existing manpower training programs but, at least in its first operating year, did not fully serve as an integrated delivery system for which it was designed.

TABLE III - PATH THROUGH WHICH A PARTICULAR PROGRAM OUTCOME IS ACHIEVED

\begin{tabular}{lrrrrrrrr}
\hline & \multicolumn{1}{c}{ NYC } \\
\hline & \multicolumn{1}{c}{ CLASS 1 } \\
End State & Job & \multicolumn{1}{c}{ Drop } & \multicolumn{1}{c}{ Unknown } & Row & Total \\
Count Pct. & Count Pct. & Count Pct. & Count & Pct. \\
\hline Orientation & 8 & 27.6 & 16 & 55.2 & 5 & 17.2 & 29 & 100.0 \\
Basic Education Only & 1 & 100.0 & 0 & 0.0 & 0 & 0.0 & 1 & 100.0 \\
Orien. + Basic Ed. & 3 & 37.5 & 4 & 50.0 & 1 & 12.5 & 8 & 100.0 \\
Direct Placement & 36 & 44.4 & 39 & 48.1 & 6 & 7.4 & 81 & 100.0 \\
Column Totals & 48 & 40.3 & 59 & 49.6 & 12 & 10.1 & 119 & 100.0 \\
\hline
\end{tabular}

${ }^{a}$ Data pertains to South and Far West only.

Clearly, numerous combinations of enrollee classes, training components, and utilization rates could be created and the results analyzed from available data. While this exercise was in fact performed and the results reported to the Department of Labor, a full-scale process simulation was not attempted due to the limited data available. The above illustrations a re intended to serve as examples of the analyses performed and results reported.

\section{Benefits and Costs by City, Training Component, and Enrollee Charac- teristics}

A complete set of data similar to those illustrated in Tables II and III was utilized in estimating "average" CEP benefits and costs. The sample benefit and cost data for the 19 CEP I's are summarized in Table IV. The benefit data were obtained by subtracting (estimated) earnings for the 52 weeks prior to training from the (projected) earnings for the 52 weeks following training. Thus, enrollees serve as their own controls, with the passage of the weeks during which training was received not expected to affect what the enrollee could have earned without training. ${ }^{8}$ The cost data for each CEP were obtained by computing the average costs by training component and adjusting these figures for the service participation rate. The average cost figuremeasures the cost of training a representative enrollee, based on the probability of his utilizing each service and the average cost of that service.

Table V illustrates how the average benefits and costs were estimated for a single city and enrollee class. The first column presents the expected (mean) annual change in earnings for those enrollees who left the program and were placed on a job after (last) utilizing the component listed on the left-hand side of the table. The second column lists the percentage of enrollees leaving each component who were placed. Column 3, adjusted earnings change, is obtained by multiplying column 1 by column 2 . Thus, the number in column 3 represents the first year earnings change for an enrollee "rep- 
TABLE IV - COMPARISON OF EXPECTED ANNUAL INCOME CHANGE OF CEP ENROLLEES AND TRAINING COST

\begin{tabular}{lrr}
\hline City & $\begin{array}{c}\text { Expected First-Year Income } \\
\text { Change, in dollarsa }\end{array}$ & $\begin{array}{c}\text { Total Training Cost } \\
\text { Per Enrollees in dollars }\end{array}$ \\
\hline 1 & N/A C & 621 \\
2 & 1,448 & N/A c \\
3 & 954 & 729 \\
4 & N/A C & 610 \\
5 & 430 & 589 \\
6 & 1,006 & 774 \\
7 & 593 & 1,206 \\
8 & 615 & 829 \\
9 & 1,131 & 627 \\
10 & N/A C & 786 \\
11 & 786 & 544 \\
12 & 1,577 & 642 \\
13 & 1,445 & 1,015 \\
14 & 831 & 858 \\
15 & 961 & 586 \\
16 & 646 & 719 \\
17 & 1,447 & 1,773 \\
18 & 256 & 714 \\
19 & N/A C & 1,793 \\
\hline
\end{tabular}

a Data obtained from sampling enrollee files.

${ }^{b}$ Data obtained from individual central records units of CEP centers.

${ }^{c}$ Indicates relevant data were not recorded by the study team. Specifically, enrollee wages were not generally recorded in one city or presented correctly in another where data tapes were used in the study; no wage data were recorded in two other cities surveyed early by the project team and no cost data were provided by one city.

resentative" of his class and city who last utilizes each respective CEPtraining component. The benefit figures presented in Table IV were computed by aggregating data illustrated in Table V over all enrollee classes and training components for each respective city.

TABLE V - PAYBACK PERIOD CALCULATION, BY COMPONENT a

\begin{tabular}{|c|c|c|c|c|c|c|}
\hline 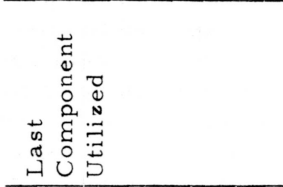 & 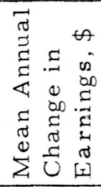 & 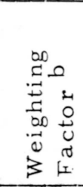 & 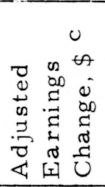 & $\begin{array}{ll}0 & 0 \\
0 & 0 \\
\pi & 0 \\
0 & 0 \\
0 & 0 \\
0 & 0 \\
4 & 0\end{array}$ & 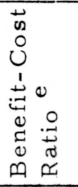 & 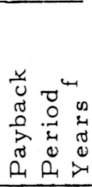 \\
\hline Job Ready & - & - & 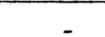 & - & & - \\
\hline Orientation & 3,041 & .306 & 931 & 593 & 14.8 & 0.7 \\
\hline Basic Education & 5,051 & .200 & 1,010 & 786 & 11.5 & 0.8 \\
\hline MDTA-Institutional & 4,111 & .389 & 1,599 & 1,869 & 8.4 & 1.5 \\
\hline MDTA-OJT & 1,200 & .500 & 600 & 4,597 & 1.2 & 15.3 \\
\hline NYC & - & - & - & - & - & - \\
\hline New Careers & 1,660 & .333 & 553 & 3,815 & 1. 4 & 12.2 \\
\hline Special Impact & - & - & - & - & - & - \\
\hline
\end{tabular}

${ }^{a}$ Data pertain to a single city and class. No one from this class enrolled in NYC; in addition, this city did not develop a Special Impact training pro- 
gram. There were generally fewer than ten observations per cell.

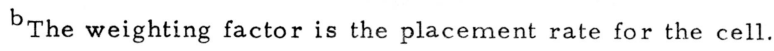

${ }^{\mathrm{C}}$ Column L multiplied by column 2 .

d Costs were computed by multiplying average cost per component by the probability of its utilization and summing over all components. The likelihood of recycling through a component was also taken into account.

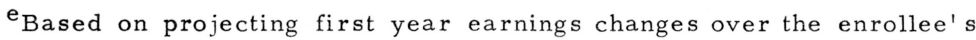
working life (age 65) and discounting them at a rate of $10 \%$.

${ }^{f}$ Computed by equating discounted benefits and costs and solving for $t$.

The average cost data presented in column 4 of Table V were much more difficult to estimate than first year benefits once benefits were defined and the necessary assumptions made) due to a) the need to follow each enrollee through the entire training process and b) the need to accurately determine "recycling" as defined in Section IIA. For example, the figure $\$ 1869$ for the MDTA Institutional component is based on:

a. the average enrollee cost of the MDTA Institutional training component, plus

b. the average enrollee cost of orientation and basic educationmultiplied by the probability of a terminating MDTA Institutionaltrainee utilizing each of these respective components, plus

c. the average enrollee cost figure obtained by adding a and b multiplied by the probability of the enrollee recycling (repeating) through these components.

The component benefit-cost ratios and pay back periods presentedin Columns 5 and 6 are computed as noted in the footnotes to Table V. It is easy to see that under alternative decision rules (e.g., accept all components whose costs would be "paid off" in less than 10 years) some components or component combinations would be accepted and others eliminated for this enrollee class and city (although the number of observations here is very small).

\section{Summary}

The previous discussion describes how a relatively complex process model was utilized to estimate benefits and costs of a manpower training program which has been labeled an "integrated delivery system." The results suggest not only that both the benefits and the costs of such a program are difficult to estimate but that a good deal of information particularly relevant for planning purposes can be lost if results are aggregated beyond the level presented in Table V. Subsequent sections illustrate some interesting behavioral hypotheses whichwere tested with the study data and some policy implications derivable from analyring the results of these tests.

\section{Illustration of Behavioral Hypotheses}

In addition to the comparison of CEP benefits and costs, it is useful to explore the sources of variation in both individual and city-wide outcomes to determine whether these sources are statistically significant. The following 
The general results of this analysis are consistent with economic theory, i. e., correct signs exist for practically all coefficients. Specifically, the results for Case I are:

a. The range in $\mathrm{R}^{2}$ for the six cities (.44 to .93) illustrates a wide range in the explanatory power of the specified set of variables with respect to the cities selected. The significance of location is tested in Hypotheses II and III.

b. The intercept (or constant term) is significant in only two of six cities, indicating that the variance in income change is explained largely by the independent variables in the equation.

c. In all cities, males realize a la rger change in income (significant in four cities) than females, as indicated by the positive coefficient attached to $X_{1}$, a shift-of-intercept, or dummy, variable while the effects of educational level $\left(\mathrm{X}_{2}\right)$ and weeks unemployed $\left(\mathrm{X}_{3}\right)$ were largely insignificant. These latter two results are not surprising, in that the change in $\mathrm{X}_{2}$ due to the programwould have been a more appropriate variable had it been measurable, while $\mathrm{X}_{3}$-here a proxy for "ability to hold a job" - is also correlated with $\mathrm{X}_{1}$.

d. Entering income, not surprisingly, is negatively correlated with in come change and is significant in all cities. ${ }^{13}$ City 2 represents a special case of this result where all enrollees were placed in occu pations at the Federal minimum wage $(\$ 1.60$ per hour or $\$ 3200$ per year for a 50 week work year). After dropping the insignificant variables, the equation becomes merely:

$$
\Delta \mathrm{Y}=\frac{3,211-1.01 \mathrm{X}_{4}}{(253.2)(0.02)}
$$

e. The appearance of both age ( $\left.\mathrm{X}_{5}\right)$ and age squared $\left(\mathrm{X}_{6}\right)$ in the equation creates a collinearity problem which essentially cancels the signifi cance in most cases. However, the signs are generally as expected (X5 - positive; $\mathrm{X}_{6}$ - negative) indicating a peak (maximum) income change at some age. In city 5 , where both coefficients were signifi $\overline{1}_{4}$ cant, maximum income change occurred at the age of 38 years. The dropping of $\mathrm{X} 6$ from the model yielded significant changes in city 4 , where the intercept almost doubled and $\mathrm{X}_{5}$ became significant $1 \mathrm{y}$ positive, and city 5 , where the intercept shifted from negative to positive.

The above results indicate the difficulties inherent in testing a behavioral relationship where the magnitude of the independent variable can be influenced to a large extent by public policy and where the sample data are of relative ly poor quality. However, the results analyzed above do have some important policy implications developed in more depth in Section IV below.

\section{Hypothesis II. Program and City Differences in Mean Income Change}

A components of variance model was used to test the importance of class and city on the variance of the mean first year income change, the percentage placed, and the mean income change adjusted for percentage for percentage placed for all CEP enrollees (denoted as the grand mean). The test was run on classes $1,2,4$, and 5 in six cities. ${ }^{15}$ The results of the se threetests are presented in Table VII. The F test yields a significant result only for "city" as a source of variation at the .05 significance level. This finding validates the hypothesis that differences in city means explain a significa $\mathrm{nt}$ portion of the variance observed about the grand mean; i. e., cities $\mathrm{make}$ a 
hypotheses were tested:

a. Hypothesis I. Variables relating to the characteristics of the programparticipant can explain the variance in first-year income changes of enrollees (tested for each of 6 cities); results can be applied to program design criteria for individuals of differing characteris tics.

b. Hypothesis II. Average first-year income changes of CEP enrollees (weighted and unweighted for placement rate) differ among classes and/or between cities; results can suggest differences in program design for broad population groups and geographic areas.

c. Hypothesis III. If Hypothesis II is validated, specific program and economic variables will explain the variance in the observed outcomes; results can suggest specific variables to consider when designing program.

d. Hypothesis IV. Program costs are related to the characteristics of enrollees processed and the geographic location of training; results can suggest important parameters of cost.

The results of analyzing each hypothesis are developed in the remainder of this section; the implications of these results for CEP operations are then i dentified as are desirable areas for further analytic development.

Hypothesis I. Determination of Variables Explaining the Variance in Individual Income Changes

This hypothesis focuses on determining the impact of the enrollee's characteristics and the program processing he receives on the change in his income. 9 The only observations admissable in this test are those on individuals whose entering and exit incomes have been recorded. ${ }^{10}$

Due to the lack of data pertaining to program services, a modified model of behavioral change was formulated and directed to explaing the vari ance in the mean change (before and after) in enrollee income (where figures are reported) in terms of the set of demographic variables and entering income itself. 11

The following variables are included in the model equation:

$\Delta \mathrm{Y} \quad$ Projected first year earnings change (enrollee benefits);

$\mathrm{X}_{1} \quad \operatorname{Sex}(0=$ female, 1 = male $) ;$

$\mathrm{X}_{2}$ Entering education level (not adjusted for quality of education or CEP impact);

$\mathrm{X}_{3} \quad$ Weeks unemployed prior to program entry (maximum $=52,1$ year);

$\mathrm{X}_{4} \quad$ Entering income (earnings for 12 month prior to CEP enrollment);

$\mathrm{X}_{5} \quad$ Age

$\mathrm{x}_{6} \quad$ Age squared $\left(\mathrm{Age}^{2}\right)^{12}$.

The results of the test for enrollees in six cities who satisfied the relevant criteria are presented by city in Table VI as Case I. 
TABLE VI

REGRESSION ANALYSIS:

EARNINGS OF INDIVIDUAL CEP ENROLLEES

\begin{tabular}{|c|c|c|c|c|c|c|c|}
\hline $\begin{array}{l}\text { City and } \\
\text { Sample }\end{array}$ & Intercept & Sex & $\begin{array}{c}\text { Edu- } \\
\text { cation }\end{array}$ & $\begin{array}{l}\text { Unemp- } \\
\text { loyment }\end{array}$ & $\begin{array}{c}\text { Entering } \\
\text { Income }\end{array}$ & Age & $\mathrm{Age}^{2}$ \\
\hline \multicolumn{8}{|l|}{ City $1 \mathrm{n}=50$} \\
\hline I. $\mathrm{R}^{2}=0.73^{\mathrm{a}}$ & $\begin{array}{l}2115.3 \\
(3146.8)\end{array}$ & $\begin{array}{l}1403.9^{c} \\
(348.5)\end{array}$ & $\begin{array}{l}126.2 \\
(99.2)\end{array}$ & $\begin{array}{l}10.1 \\
(8.6)\end{array}$ & $\begin{array}{l}-0.85^{c} \\
(0.11)\end{array}$ & $\begin{array}{l}-26.0 \\
(237.8)\end{array}$ & $\begin{array}{r}0.57 \\
(4.4)\end{array}$ \\
\hline II. $\mathrm{R}^{2}=0.73^{\mathrm{b}}$ & $\begin{array}{l}1747.5 \\
(1277.7) \\
\end{array}$ & $\begin{array}{l}1393.0^{\mathrm{C}} \\
(313.7)\end{array}$ & $\begin{array}{l}124.6 \\
(91.2) \\
\end{array}$ & $\begin{array}{l}10.2 \\
(7.9) \\
\end{array}$ & $\begin{array}{l}-0.85^{c} \\
(0.11) \\
\end{array}$ & $\begin{array}{r}4.75 \\
(23.5) \\
\end{array}$ & - \\
\hline \multicolumn{8}{|l|}{ City $2 n=147$} \\
\hline I. $\mathrm{R}^{2}=0.93$ & $\begin{array}{l}3211.5^{c} \\
(253.2)\end{array}$ & $\begin{array}{c}14.3 \\
(49.9)\end{array}$ & $\begin{array}{l}-2.7 \\
(8.9)\end{array}$ & $\begin{array}{l}-0.29 \\
(2.16)\end{array}$ & $\begin{array}{l}-1.01^{c} \\
(0.02)\end{array}$ & $\begin{array}{c}4.61 \\
(14.0)\end{array}$ & $\begin{array}{l}-0.09 \\
(0.19)\end{array}$ \\
\hline II. $\mathrm{R}^{2}=0.93$ & $\begin{array}{l}3308.7^{c} \\
(243.5) \\
\end{array}$ & $\begin{array}{r}8.7 \\
(47.3) \\
\end{array}$ & $\begin{array}{l}-2.4 \\
(8.7) \\
\end{array}$ & $\begin{array}{l}-0.20 \\
(2.10) \\
\end{array}$ & $\begin{array}{l}-1.01^{c} \\
(0.02)\end{array}$ & $\begin{array}{l}-1.76 \\
(2.18) \\
\end{array}$ & - \\
\hline \multicolumn{8}{|l|}{ City $3 n=27$} \\
\hline I. $\mathrm{R}^{2}=0.86$ & $\begin{array}{c}779.9 \\
(1202.9)\end{array}$ & $\begin{array}{c}706.7^{c} \\
(247.2)\end{array}$ & $\begin{array}{l}106.9^{c} \\
(57.5)\end{array}$ & $\begin{array}{r}20.0^{c} \\
(7.6)\end{array}$ & $\begin{array}{r}-0.82^{c} \\
(0.08)\end{array}$ & $\begin{array}{c}35.5 \\
(91.2)\end{array}$ & $\begin{array}{r}-0.33 \\
(1.3)\end{array}$ \\
\hline II. $\mathrm{R}^{2}=0.86$ & $\begin{array}{l}984.7 \\
(645.1)\end{array}$ & $\begin{array}{l}702.3^{c} \\
(212.3)\end{array}$ & $\begin{array}{l}113.6^{\mathrm{C}} \\
(42.0)\end{array}$ & $\begin{array}{r}19.9^{c} \\
(6.5) \\
\end{array}$ & $\begin{array}{r}-0.82^{c} \\
(0.07) \\
\end{array}$ & $\begin{array}{r}15.9 \\
(10.6) \\
\end{array}$ & - \\
\hline \multicolumn{8}{|l|}{ City $4 n=52$} \\
\hline I. $\mathrm{R}^{2}=0.53$ & $\begin{array}{l}1270.4 \\
(1024.8)\end{array}$ & $\begin{array}{c}385.6^{d} \\
(223.1)\end{array}$ & $\begin{array}{l}99.2^{\mathrm{C}} \\
(46.7)\end{array}$ & $\begin{array}{r}-13.3 \\
(8.2)\end{array}$ & $\begin{array}{l}-0.9^{c} \\
(0.15)\end{array}$ & $\begin{array}{l}100.3 \\
(68.7)\end{array}$ & $\begin{array}{c}-1.1 \\
(1.1)\end{array}$ \\
\hline II. $\mathrm{R}^{2}=0.52$ & $\begin{array}{l}2127.2^{c} \\
(587.9) \\
\end{array}$ & $\begin{array}{r}373.6^{\mathrm{d}} \\
(209.8) \\
\end{array}$ & $\begin{array}{r}112.8^{c} \\
(42.2) \\
\end{array}$ & $\begin{array}{r}-13.1 \\
(7.7) \\
\end{array}$ & $\begin{array}{l}-0.9^{c} \\
(0.14) \\
\end{array}$ & $\begin{array}{l}29.0^{\mathrm{C}} \\
(11.3) \\
\end{array}$ & - \\
\hline \multicolumn{8}{|l|}{ City $5 n=120$} \\
\hline I. $\mathrm{R}^{2}=0.44$ & $\begin{array}{l}-2045.6 \\
(1367.9)\end{array}$ & $\begin{array}{l}1308.4 \\
(241.9)\end{array}$ & $\begin{array}{c}34.2 \\
(57.7)\end{array}$ & $\begin{array}{l}8.2 \\
(8.3)\end{array}$ & $\begin{array}{r}-0.9^{c} \\
(0.1)\end{array}$ & $\begin{array}{l}311.6^{c} \\
(90.0)\end{array}$ & $\begin{array}{l}-4.1^{c} \\
(1.4)\end{array}$ \\
\hline II. $\mathrm{R}^{2}=0.40$ & $\begin{array}{l}1143.1 \\
(839.0) \\
\end{array}$ & $\begin{array}{l}1308.4^{c} \\
(243.6)\end{array}$ & $\begin{array}{r}62.0 \\
(57.3) \\
\end{array}$ & $\begin{array}{l}11.1 \\
(8.2) \\
\end{array}$ & $\begin{array}{l}-0.8^{c} \\
(0.11) \\
\end{array}$ & $\begin{array}{r}50.3^{c} \\
(14.2) \\
\end{array}$ & - \\
\hline \multicolumn{8}{|l|}{ City $6 n=127$} \\
\hline I. $\mathrm{R}^{2}=0.37$ & $\begin{array}{l}4499.0^{c} \\
(1461.6)\end{array}$ & $\begin{array}{c}285.1 \\
(243.0)\end{array}$ & $\begin{array}{c}-192.3^{c} \\
(87.0)\end{array}$ & $\begin{array}{l}-5.9 \\
(6.1)\end{array}$ & $\begin{array}{l}-0.8^{c} \\
(0.1)\end{array}$ & $\begin{array}{l}108.0 \\
(76.0)\end{array}$ & $\begin{array}{l}-1.7 \\
(1.2)\end{array}$ \\
\hline II. $\mathrm{R}^{2}=0.36$ & $\begin{array}{l}5788.1^{c} \\
(1134.7)\end{array}$ & $\begin{array}{r}295.0 \\
(238.2) \\
\end{array}$ & $\begin{array}{r}-176.6^{c} \\
(84.7) \\
\end{array}$ & $\begin{array}{l}-5.1 \\
(5.9) \\
\end{array}$ & $\begin{array}{l}-0.8^{c} \\
(0.09) \\
\end{array}$ & $\begin{array}{l}-212.3 \\
(130.8) \\
\end{array}$ & - \\
\hline $\begin{array}{l}{ }^{\mathrm{a}} \mathrm{Age}^{2} \text { in } \\
{ }^{\mathrm{b}} \mathrm{Age}^{2} \text { ex } \\
{ }^{\mathrm{c}} \text { Indicate } \\
{ }^{\mathrm{d}} \text { Indicate }\end{array}$ & $\begin{array}{l}\text { uded. } \\
\text { luded. } \\
\text { coeffic } \\
\text { coeffic }\end{array}$ & . & . & 05 & 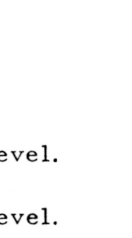 & & \\
\hline
\end{tabular}


difference in relative outcomes (first year changes only), although enrollee class (i.e., socio-demographic characteristics) per se does not.16

The results indicate the desirability of both realignment of CEP along city lines (rather than writing uniform guidelines for all cities) and further investigation of the differences in outcome resulting from enrollment in each of the CEP training components. It is suggested from the differences in the economy and institutions of the cities studied that programs must be structured specifically for individual cities and the relevant target populations.

TABLE VII - ANALYSIS OF VARIANCE OF CEP BENEFITS

\begin{tabular}{lcccc}
\hline Source of & Sum of & Degrees of & Mean & \\
Variation & Squares & Freedom & Square & F Ratio \\
\hline & Mean Income Change &
\end{tabular}

$\begin{array}{lrrrr}\text { Class } & 206525 & 3 & 68841 & 0.24 \\ \text { City } & 6533388 & 5 & 1306677 & 4.49 \\ \text { Residual } & 4363553 & 15 & 290903 & - \\ \text { Total } & 11103467 & 23 & - & - \\ & & & \end{array}$

\begin{tabular}{|c|c|c|c|c|}
\hline Class & 23514 & 3 & 7838 & 0.61 \\
\hline City & 300228 & 6 & 50038 & 3.87 \\
\hline Residual & 232727 & 18 & 12929 & \\
\hline \multirow[t]{2}{*}{ Total } & 556470 & 27 & & \\
\hline & \multicolumn{4}{|c|}{ Adjusted Mean Income Change } \\
\hline Class & 160726 & 3 & 53575 & 0.69 \\
\hline City & 3020417 & 5 & 604083 & 7. 74 \\
\hline Residual & 1170796 & 15 & 78053 & \\
\hline Total & 4351940 & 23 & $=$ & $\overline{ }$ \\
\hline
\end{tabular}

Hypothesis III. Factors Explaining the Variance in Adjusted City Income Changes

Once city differences in income change had been found to be statistically significant, the next logical step involved the determination of the variables explaining this result. For this test, linear multiple regression was used with the following independent variables:

$\Delta \mathrm{Y}$ First year earnings change adjusted for placement rate;

$\mathrm{X}_{1}$ City unemployment rate (average of September 1967 and 1968);

$\mathrm{X}_{2}$ Size of the city work force (average of September 1967 and 1968);

$\mathrm{X}_{3}$ Region $(0=$ South, i.e., Birmingham, Houston, New Orleans, San Antonio, 1 = otherwise).

The results of this test indicate the insignificance of the independent variables in explaining the variance in $\Delta \mathrm{Y}$ even when a step-use approach was attempted to eliminate multicollinearity. The general conclusion points to both agg regation and quantification problems: aggregation with respect to the difficulty of specifying the labor market that was effectively open to enrollees, and quantification with respect to the identification of variables reflecting the influence of individual community leaders, labor unions, and other institutions that may be generally responsible for the success of such manpower training programs as CEP. Again, it is suggested that programs be tailored to uniquelocal conditions. 
Hypothesis IV. Cost-Estimating Relationship (CER)

This hypothesis was formulated to explain the variance in program cost figures per enrollee in terms of characteristics of the enrollees and the program over a cross-section of CEP cities. This CER, as opposed to an economic cost function, attempts to relate cost to variables that constitute proxies for operating variables. The assumption of efficient resource utilization is still required when testing a CER.

The estimated CER relates average enrollee cost to the following variables:
AC Average CEP training cost (per enrollee);
$\mathrm{X}_{1}$ Percentage of enrollees who are male (i.e., the effect of enroll ee s ex);
$\mathrm{X}_{2}$ Percentage of enrollees age 22 to 44 (i.e., the effect of age);
$\mathrm{X}_{3} \quad$ Percentage of enrollees with at least a twelfth-grade education;
$\mathrm{X}_{4} \quad$ Percentage of enrollees unemployed 27 weeks or more befor e entry into program;
$\mathrm{X}_{5} \quad$ Percentage of enrollees who are welfare recipients;
$\mathrm{X}_{6} \quad$ Percentage of enrollees below the income poverty level;
$\mathrm{X}_{7} \quad$ Index reflecting differences in regional geography measu $\mathrm{r}$ ed from 10 to 90 in increments of 10 corresponding to the nine re- gional manpower areas.

The inclusion of all the foregoing variables in a single equation led to degrees of freedom and multicollinearity problems. Hence, a step-wise procedure was adopted and the following statistically significant relationship emerged:

$$
\begin{aligned}
& \mathrm{AC}=\underset{(240.5)}{583.9}+\underset{(6.9)}{17.5 \mathrm{X}_{3}}+\frac{5.9 \mathrm{X}_{7}}{(2.6)} \\
& \mathrm{R}^{2}=0.42 \\
& \text { Observations }=18 \mathrm{CEPs}, \text { annual figure. }
\end{aligned}
$$

The positive relationship between average cost and educational level cannot be explained on logical grounds. However, the significance of the regional index indicates, as in the case of the benefit hypotheses (I and II), that the variance in costs is explained by regional factors that have not been quantified in variables $X_{1}$ through $X_{6}$.

\section{Study Conclusions and Recommendations to the Manpower \\ Administration}

This section summarizes the results of the study as they werepresented to Department of Labor officials. The objective of this presentation was to provide a government agency with managerially useful statements pertaining to program operations, effectiveness, and costs. While the study was limited in its comprehensiveness by the design and data quantity and quality noted previously, several study conclusions pertinent to Manpower Administration functions of planning and evaluation were derivable (in large part) from the hypotheses tests and analysis performed in the preceding section. 


\section{A. CEP Operating System}

Although they follow the basic guidelines enunicated by DOL, the CEP centers are quite individualized in nature and use designated training components in a variety of ways determined partially by the cooperation received from private and public sector organizations and the relevant state employment service. The tests performed in Section III served to verify this finding whichwas based also upon the observations of the study team in the $19 \mathrm{ci}$ ties. For planning persons, then, a good deal of knowledge pertaining to local conditions is necessary both to select a set of cities and funding levels for program implementation and to choose between competing contractors within a city.

The difficulty of both recording and interpreting cost data indicate that all cash flows should be recorded on a component basis; records on all nonCEP funded costs (e.g., those borne by city governments or private firms, if any) and the use of volunteer assistance should also be maintained. In addition, specific enrollee flows and costs should be isolated for each component cycle and summarized periodically according to the information need noted in Section B.

The availability of and procedures for obtaining detailed information on environmental variables should be established and summarizations of current data maintained. Cooperation between CEP and existing state and local economic development groups (who generally collect such data) should be fostered as a means for ensuring access to needed information.

\section{B. Effectiveness of CEP in Placing Enrollees in Permanent Unsubsidized Jobs}

Placement rates (i.e., percentage of CEP enrollees employed) varied greatly according to demographic characteristics, city, and CEP components utilized in processing the enrollees; however, the data were insufficient to evaluate some of these results on a statistical basis. Application forms must provide accurate information regarding personal characteristics (age, sex, race, educational attainment); geographic background (e.g., place of school ing); specific skills (including all formal and informal schooling, details of all jobs held); labor force participation (particularly with respect to women and teenagers); and earnings for the previous 12 months including hourly wage, hours worked per week, and weeks worked during the year. Forms must be accurately maintained which provide detailed information regarding each component utilized by the enrollee (including length of enrollment,performance,etc.).

Follow-up must be performed in greater depth and over a longer time horizon than at present; in addition, nonparticipants in the community should be sampled to facilitate measurement of changes in enrollee earnings that are due to the program itself.

In the short run most enrollees were placed in slots in (partially) subsidized work areas - either in the private (MDTA) or the public (NYC, New Careers, Special Impact) sectors. As previously noted, follow-up analysis was insufficient to determine the extent of movement into the permanent, unsubsidized job category. In many cities, the earnings of those placed did show significant improvement; however, the test of Hypothesis I indicated that all enrollees in one city were placed at the same wage ( $\$ 1.60$ per hour) regardless of skill level and, in another, short-term placements in Neighborhood Youth Corps (NYC) were a definite characteristic. Additionally, placement rates reported by a number of CEPs were significantly higher than those recorded by the survey teams. This disparity is apparently the result of both cloudly definitions of "placement" and multiple recording by some centers of placements for enrollees who "recycle" through the process. 


\section{Expenditures for Enrollee Training}

CEP expenditures are classified into three categories:

1. Operating costs of training;

2. Enrollee wages during training;

3. Stipends (e.g., MDTA allowances) paid enrollees during training.

For the CEPs visited, the range for each category (computed on a perenrollee basis) was:

1. $\$ 567-\$ 2,147$;

2.. $\$ 0-\$ 688$;

3. $\$ 22-\$ 650$.

Based on placement rates reported by the CEP centers, the operating costs per placed enrollee ranged from $\$ 651$ to $\$ 5,852$. Again, this finding serves to verify that careful analysis of CEP along a number of dimensions is warranted before generalized conclusions pertaining to "CEP performance" are drawn. 
FOOTNOTES

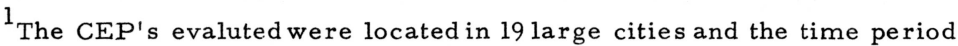
was roughly July 1967 to September 1968. The cities included: Atlanta, Baltimore, Birmingham, Boston, Chicago, Cleveland, Detroit, Houston, Los Angeles, Newark, New Orleans, New York, Oakland, Philadelphia, Pittsburgh, St. Louis, San Antonio, San Francisco, and Washington, D. C.

2 M. E. Borus, "A Benefit-Cost Analysis of the Economic Effectiveness of Retraining the Unemployed," Yale Economic Essays, Volume IV, 1964, and Glen Cain, "Benefit/Cost Estimates for Jobs Corps," Institute for Re search on Poverty, The University of Wisconsin, 1967.

${ }^{3}$ Charles Schultze, The Politics and Economics of Public Spending, The B rookings Institution, $19 \overline{968}$.

${ }^{4}$ U.S. Department of Labor, Evaluation of the CEP, September 1968.

${ }^{5}$ The points $\mathrm{A}, \mathrm{B}$, and $\mathrm{C}$ refer to physical locations to which enrollees move and would be developed further in a full-blown diagram of the process. This flow chart was utilized in setting up the data collection sheets for field work from which the subsequent analysis was performed.

6 The Sampling period was divided into two phases. During the first phase, the Northeast and Midwest were sampled with no information recorded for specific enrollees; during the second phase, the South and Far West were sampled with specific characteristics of each enrollee recorded on a single sheet and hence traceable to that enrollee. The particular sample utilized will be noted in each case where data a re presented.

${ }^{7}$ This sample was taken from seven Southern and Far Western states only.

${ }^{8}$ Additionally, earnings foregone during training a re assumed to be zero. While this assumption most likely leads to the understatement of costs, little data pertaining to this figure were available to the study team.

${ }^{9}$ Although it was also anticipated that the receipt of CEP supportive services, e.g., day care, would be used as an independent variable, data on relevant services were generally not available from the CEP central records unit.

${ }^{10}$ While this restriction could lead to bias, it was not felt that individuals whose records were filled out incompletely differed significantly from those whose records were completed in full.

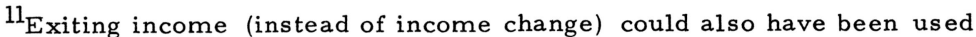
as the dependent variable, with a change in meaning of the coefficient for en tering income in the model. Either case will lead to biased estimates of the coefficients as discussed subsequently. The extent of this bias could not be determined with the data available.

12 This formulation tests the additional hypothesis that earnings change is a parabolic function of age, reaching a maximum (the coefficient $X$ positive and that of $\mathrm{X}^{2}$ negative) at some age.

${ }^{13}$ It can be shown that the coefficient would be -1 if its effect on income change were nil, since

$$
\mathrm{Y}=\text { Exit Income }-\mathrm{X}_{4} \text {. }
$$


Thus the derivation of the coefficient from -1 (towards 0) measures the net positive effect of this variable on income change.

${ }^{14}$ Take $\underline{\delta \text { IncChg }}$ and set equal to zero. From TableVI, this equation is: ઈage $\quad 0=\frac{\delta \text { IncChg }}{\delta \text { age }}=311.6-8.2$ age.

Solving for age yields 38. 0 . The raw data for this city indicate higherincome changes for classes 2 and 5 (age 22-44) than for the other classes which corroborates the analytic finding.

${ }^{15}$ The cities used were Cleveland, Houston, Los Angeles, Oakland, San Antonio, and San Francisco. The restriction placed on the number of classes was a result of the empty data cells for classes 3 and 6. New Orleans was included in the analysis of placement rates only.

${ }^{16}$ Wide variations do appear between training program results, regardless of class and city, but the sample size was insufficient to justify the inclusion of this factor as a dimension in the analysis of variance. 


\section{REFERENCES}

Baumol, W. J., "On the Social Rate of Discount," American Economic Review, Volume LVIII, September 1968, pp. 788-802.

Becker, G.S. , Human Capital, National Bureau of Economic Research, New York, 1964.

Besen, S.M., et al., "Cost-Effectiveness Analysis for the War on Poverty," Washington ORSA Symposium, 1967.

Borus, M.E., "A Benefit-Cost Analysis of the Economic Effectiveness of Retraining the Unemployed," Yale Economic Essays, Volume IV, 1964.

Borus, M.E. and W. R. Tash, "Evaluating the Impact of Manpower Programs: An Evaluation Handbook" (mimeographed), Department of Labor, Washington, D. C. , 1968.

Cain, Glen, "Benefit/Cost Estimates for Job Corps," Institute for Research on Poverty, The University of Wisconsin, 1967.

Dunlap and Associates, Evaluation of Neighborhood Youth Corps Projects, February 1966.

Kershaw, J.A., "The Need for Better Planning and Coordination," in R. A. Gordon, ed., Toward a Manpower Policy, John Wiley and Sons, Inc., 1967.

Main, E. D., "A Nationwide Evaluation of MDTA Institutional Job Training Programs, "The Journal of Human Resources, Volume III, 1968, pp. 159-170.

Mangum, Garth, MDTA: Foundation of Federal Manpower Policy, John Hopkins Press, 1968.

McKean, Roland, Efficiency in Government Through Systems Analysis, John Wiley and Sons, Inc., 1963.

Prest, A. R., and Ralph Turvey, "Cost-Benefit Analysis: A Survey," Surveys of Economic Theory, Resource Allocation, Volume III, prepared for the American Economic Association and the Royal Economic Society, St. Martin's Press, 1967.

Priesman, I. M. , ed. , CEP Planning Service Book, System Development Corporation, April 1968.

Proceedings, Benefit-Cost Analysis of Manpower Training Programs, North American Conference (mimeographed papers), University of Wisconsin, May 1969.

Ribich, Thomas, Education and Poverty, The Brookings Institution, 1968.

Schultze, Charles, The Politics and Economics of Public Spending, The Brookings Institution, 1968.

Thurow, L.C., "The Role of Manpower Policy in Achieving Aggregative Goals," in R.A. Gordon, ed., Toward A Manpower Policy, John Wiley and Sons, Inc., 1967.

U.S. Congress, Joint Economic Committee, The Analysis and Evaluation of Public Expenditures: The PPB System (3 volumes), 1969. 
U.S. Department of Labor, Evaluation of the CEP, September 1968.

U.S. Department of Labor, Manpower Report of the President, January 1969.

Weisbrod, Burton A., "Income Redistribution Effects and Benefit-Cost Analysis," in S. B. Chase, Jr., ed., Problems in Public Expenditure Analysis, The Brookings Institution, 1968, pp. 177-209. 